\title{
Double-burden of malnutrition among the indigenous peoples (Orang Asli) of Peninsular Malaysia
}

\author{
C. Y. Wong, M. S. Zalilah", E. Y. Chua, S. Norhasmah, Y. S. Chin and A. Siti Nur'Asyura
}

\begin{abstract}
Background: Double-burden of malnutrition (DBM) is an emerging public health concern among the Orang Asli (indigenous peoples) of Peninsular Malaysia. This study aimed to identify the presence of DBM at the community and household levels in Orang Asli population and its associated demographic and socio-economic factors.

Methods: This cross-sectional study was conducted in 11 Orang Asli villages surrounding the Krau Wildlife Reserve, Peninsular of Malaysia from October 2011 to January 2012. Of 438 households, a total of 981 adults and 304 children who met the study criteria agreed to participate. About 160 households were further selected with pairs of children aged 3-59 months and non-pregnant mothers aged 15-55 years. Demographic and socio-economic data were obtained using interviewer-administered questionnaire while weight and height were measured using standard procedures. Double-burden of malnutrition was defined as overweight/obese mother-underweight child (OWOBM/UWC), overweight/obese mother-stunted child (OWOBM/STC) or overweight/obese mother-underweight or/and stunted child (OWOBM/UWSTC). Binary logistic regression identified the demographic and socio-economic factors associated with double-burden households.
\end{abstract}

Results: About $26 \%$ of overweight and obese adults coexisting with high proportions of underweight (49\%) and stunted (64\%) children in these Orang Asli villages. There was a higher prevalence of households with OWOBM/ UWSTC (20 \%) and OWOBM/STC (19.4\%) than households with OWOBM/UWC (12.5\%). Boys $(P<0.05)$, older age mothers $(P<0.05)$, mothers with higher education $(P<0.05)$ and households with income per capita less than USD 29.01 (RM 97.00) $(P<0.01)$ were associated with higher odds of OWOBM/STC. Jah Hut $(P<0.05)$ and higher number of children $(P<0.05)$ were significantly associated with lower odds of OWOBM/UWC.

Conclusions: The occurrence of double-burden of malnutrition in Orang Asli population deserves attention. Poverty reduction, access to quality diet and improved health and nutrition literacy are among strategies that could address the coexistence of DBM in this population.

Keywords: Double-burden of malnutrition, Demographics and socio-economics, Indigenous peoples, Orang Asli

\section{Background}

In many low- and middle-income countries, the persistence of undernutrition in children is accompanied by increasing overweight and obesity in older children, adolescents and adults. This phenomenon, known as "double-burden of malnutrition" (DBM), is emerging within countries, communities and even households

\footnotetext{
*Correspondence: zalilahms@upm.edu.my

Department of Nutrition and Dietetics, Faculty of Medicine and Health Sciences, Universiti Putra Malaysia, 43400 UPM, Serdang, Selangor Darul Ehsan, Malaysia
}

\section{Biomed Central}

[1-5]. National surveys from six low- to middleincome countries showed that $3.7-15.5 \%$ of households were with underweight and overweight members [1], while national surveys from 42 developing countries in Africa, Asia and Latin America reported that there were $0.9-16.0 \%$ of households with a stunted child and an overweight or obese mother [2]. This DBM phenomenon is an emergent public health problem that could lead to impaired child growth and cognitive development which in turn will dramatically increase the risk of obesity and non-communicable 
chronic diseases as well as impaired social and economic productivity in adulthood [6-8]. In addition, DBM profoundly complicates nutritional interventions because under- and over-nutrition have so far been treated as distinct nutritional problems when in fact they may share similar determinants $[3,9]$.

The DBM phenomenon is due to interaction of changes related to demographic and socio-economic status, traditional food patterns and lifestyle [10]. Studies have shown that DBM is more prevalent in urban than rural areas of developing countries, particularly among low income households, but gradually increasing in the rural areas $[1,3,9,11]$. Factors such as household size, number of children, maternal (age, marital status, education and employment status) and child factors (age and sex) were also associated with risk of DBM households [3, 9, 11-13].

Indigenous peoples make up approximately $4.5 \%(\sim 300$ million) of the global population and they are still among the poorest and most marginalized groups with poor health and social outcomes [14]. Indigenous peoples are not spared from DBM. For example, over half of the indigenous adults in Australia were overweight and obese despite the persistence of undernutrition in children (10-14 \%) [15]. Likewise, the First National Survey of Indigenous Peoples in Brazil reported that about $6 \%$ and $26 \%$ of children were underweight and stunted, while $46.1 \%$ of adults were overweight and obese $[16,17]$. The increasing prevalence of DBM phenomenon is parallel to the rising prevalence of diabetes mellitus, hypertension and cardiovascular diseases among indigenous peoples in Brazil [17], Australia [18, 19] and Canada [20].

The indigenous peoples of Peninsular Malaysia (Orang Asli) are also experiencing a high rate of obesity, hypertension and diabetes even though they contribute to $0.7 \%$ of the total population in Peninsular Malaysia [21]. Several studies showed that approximately 10-35\% of Orang Asli adults in Peninsular Malaysia were overweight and obese, yet more than half of the children were underweight and stunted [22-25]. In an earlier study, the prevalence of diabetes mellitus $(1.3 \%)$ and impaired glucose tolerance (10.7 \%) was significantly higher among Orang Asli living in rural area than those living in the remote forest $(0.0 \%$ and $3.3 \%$ respectively) [26]. Wan Nazaimoon \& Suraiami [27] reported that $22.7 \%$ of female Orang Asli adults in Peninsular Malaysia had metabolic syndrome, with the prevalence of diabetes mellitus and impaired fasting glucose was $8.4 \%$ and $16.8 \%$, respectively. A recent study among the Orang Asli of Peninsular Malaysia showed that the prevalence of obesity, abdominal obesity, hypertension and diabetes mellitus was $16.8 \%, 38.4 \%, 29.6 \%$ and $4.6 \%$, respectively [28].

While undernutrition still prevails in Orang Asli children $[22,25]$, obesity and metabolic risks are increasingly prevalent among the Orang Asli adults. This study aimed to assess the presence of double-burden of malnutrition at the community and household levels by assessing the nutritional status of Orang Asli adults and children. In addition, we further investigated the demographic and socio-economic characteristics that differentiate normal and double-burden of malnutrition households in this community.

\section{Methods}

\section{Study design and location}

This cross-sectional study was conducted in Krau Wildlife Reserve (KWR) from October 2011 to January 2012. The reserve covering 62,395 hectares is located near the Benom Mountain in central state of Pahang, Malaysia [29]. According to the Malaysia Department of Orang Asli Development [30], there are 11 Orang Asli villages around the KWR with approximately 3,636 individuals living in 833 households. The major Orang Asli sub-tribes living in these villages are Jah Hut and Che Wong of Senoi ethnic group, and Temuan of Proto Malay ethic group [30].

\section{Study subjects}

A total of 533 households were identified from the 11 Orang Asli villages around KWR but only 485 households agreed to participate in this study. The other 300 households could not be visited due to lack of accessibility to the households (i.e. residing in the forest interior or at the other side of Kuala Krau River) or households no longer exist.

There were two phases of study. In the first phase (community level), a total of 1,521 adults aged 18 years and above and 363 children below 5 years of Jah Hut, Temuan and Che Wong tribes, with no health disabilities from the 485 households were identified. Pregnant women and mothers who gave birth less than 3 months prior to the measurements were excluded. However, only 981 adults and 304 children completed weight and height measurements. In the second phase (household level), the 485 households were further screened for mother-child pairs. A total of 160 mother-child pairs met the inclusion criteria of at least one child (659 months of age) and non-pregnant mother (15-55 years of age). For households with more than one mother-child pairs, only one pair was randomly selected. In addition, if a family has 2 or more children in the age range of 6-59 months, the oldest one was selected to the mother-child pair (index child).

\section{Measurements}

Demographic and socio-economic characteristics

Information on household characteristics (e.g. ethnicity, household size, number of children, number of schooling 
children and household income), maternal (e.g. age, marital status, education, occupation, income) and child profile (e.g. sex, age) were obtained from household heads (mainly fathers) or mothers, using a set of pre-tested administered questionnaire. Information on age was recorded based on identification cards or birth certificates.

\section{Physical measurement}

Weight and height measurements were taken using standard procedures [31]. Tanita digital weighing scale (Tanita Corporation, Tokyo, Japan) and SECA stadiometer (Vogel and Halke \& Co., Hamburg, Germany) were used to measure weight and height of children ( 2 years and above) and adults, to the nearest $0.1 \mathrm{~kg}$ and $0.1 \mathrm{~cm}$, respectively. A SECA model 334 infantometer (SECA Gmgh \& Co. Kg, Hamburg, Germany) was used to measure the recumbent weight and length of infants and young children (less than 2 years), to the nearest $0.01 \mathrm{~kg}$ and $0.1 \mathrm{~cm}$, respectively. Age- and sex-specific z-scores for weight-for-age (WAZ), height-for-age (HAZ) and body mass index-for-age (BAZ) of children (below 5 years) were calculated using WHO Anthro software (version 3, 2009). Underweight, stunting and thinness for children were defined as WAZ, HAZ and $\mathrm{BAZ}<-2$ standard deviation (SD) whereas overweight for children were defined as $B A Z \geq 2$ standard deviation [32]. Body mass index (BMI) of adults was calculated from the weight and height measurements. Underweight and overweight/obesity for mother were defined as $\mathrm{BMI}<18.5 \mathrm{~kg} / \mathrm{m}^{2}$ and $\mathrm{BMI}>24.99 \mathrm{~kg} / \mathrm{m}^{2}$, respectively [31].

\section{Classifications of the Orang Asli's nutritional status at community and household levels}

Weight-for-age (WAZ) and height-for-age (HAZ) for children and body mass index (BMI) for adults and mothers were used to assess nutritional status of the Orang Asli at the community and household levels. At the community level, we defined DBM as having a high prevalence of stunting/underweight coexisting with a high prevalence of overweight/obesity within a community/population $[1,33]$. The "high prevalence" was defined as any value greater than the expected prevalence of $15 \%$ for overweight/obesity and $5 \%$ for stunting based upon the range of BMI and height in the reference or standard populations [34]. At the household level, we defined DBM as the coexistence of an overweight or obese mother (OWOBM) and an underweight and/or stunted child (UWSTC) within the same household. By using the 2 indicators of WAZ and HAZ for children and BMI for mothers, the 6 classifications of nutritional status of mother-child pairs are presented in Table 1.

\section{Ethics approval}

The study protocol was approved by the Medical Research Ethics Committee of the Faculty of Medicine and Health Sciences, Universiti Putra Malaysia. Permission to conduct this study was obtained from the Malaysia Department of Orang Asli Development (JAKOA) and Department of Wildlife and National Parks Peninsular Malaysia (PERHILITAN). Prior to data collection, researchers verbally informed household heads about the study and obtained initialized or verbal informed consent from household heads or mothers.

\section{Statistical analysis}

IBM SPSS Statistics 20.0 (IBM Corporation, New York, USA) was used for data analysis. All variables were presented as mean, standard deviation and frequency. Preliminary analysis included the descriptive statistics on nutritional status of adults and children, which was used to assess the presence of DBM at the community and household levels. Binary logistic regression models were further used to identify the demographic and socio-economic factors associated with DBM households (OWOBM/UWC: overweight or obese mother/underweight child; OWOBM/STC: overweight or obese mother/ stunted child; OWOBM/UWSTC: overweight or obese mother/underweight or/and stunted child). The reference group for all analyses was normal households (NWM/ NWC: normal weight mother and child; NWM/NHC: normal weight mother/normal height child; NWM/NWNHC: normal weight mother/normal weight and height child). In the binary logistic regression models, univariate logistic

Table 1 Classifications of nutritional status of mother-child pairs

\begin{tabular}{llll}
\hline Classification & $B M I_{\text {mother VS. WAZ }}$ child & $B M I_{\text {mother }}$ Vs. HAZ & BMI $_{\text {mother }}$ VS. WAZ/HAZ \\
\hline 1. Double burden household & OWOBM/UWC & OWOBM/STC & OWOBM/UWSTC \\
2. Mother normal/child normal & NWM/NWC & NWM/NHC & NWM/NWNHC \\
3. Mother normal/child undernutrition & NWM/UWC & NWM/STC & NWM/UWSTC \\
4. Mother overweight or obesity/child normal & OWOBM/NWC & OWOBM/NHC & OWOBM/NWNHC \\
5. Mother underweight/child normal & UWM/NWC & UWM/NHC & UWM/NWNHC \\
6. Mother underweight/child undernutrition & UWM/UWC & UWM/STC & UWM/UWSTC \\
\hline
\end{tabular}

OWOBM overweight or obese mother, NWM normal weight mother, UWM underweight mother, UWC, underweight child, NWC normal weight child, STC stunted child, NHC normal height child, UWSTC underweight or/and stunted child, NWNHC normal weight and height child 
regression analysis was first used to assess the association of independent variable individually with the dichotomous dependent variable. Results were presented as odds ratios (OR) with $95 \%$ confidence interval (CI). Then, we further estimated the adjusted odds ratios (adj. OR) by adding the independent variables that were significant at univariate level (lenient cut-off point of $P<0.25$ ) or that needed to be included in order to control for confounding, in multivariate analysis. Model fit was determined by the Hosmer-Lemeshow statistic. Statistical significance was set at $P<0.05$.

\section{Results}

\section{Demographic and socio-economic characteristics}

A total of 981 adults (86.7 \% Jah Hut, $7.0 \%$ Temuan and $6.2 \%$ Che Wong) from 485 Orang Asli households participated in this study (Table 2). This study comprised of $46 \%$ men and $54 \%$ women with a mean age of $37.3 \pm 14.9$ years. The mean year of schooling was $3.7 \pm 4.2$ years. More than $70 \%$ of households had per capita monthly income below the poverty line for Peninsular Malaysia of USD 58.02 (RM 194) [35]. The 160 Orang Asli households with mother-child pairs comprised of $87.5 \%$ Jah Hut, $4.4 \%$ Temuan and $8.1 \%$ Che Wong (Table 2). There were $59 \%$ and $41 \%$ of boys and girls, respectively with a mean age of $33.7 \pm$ 16.4 months. The mean age of mothers was $29.7 \pm$ 7.4 years with a majority $(88 \%)$ in the age range of 18-39 years. Most mothers had low educational level (4.1 \pm 3.6 years) and were housewives or unpaid family workers (91\%).

\section{Nutritional status: the occurrence of double-burden of malnutrition}

At the community level, about $13 \%, 19 \%$ and $7 \%$ of the adults were underweight, overweight and/or obese, respectively (Table 3 ). While $17 \%$ of mothers were underweight, there were more than one-fourth of mothers $(28 \%)$ were overweight and obese. In addition, high proportions of children were stunted $(64.2 \%)$ and underweight $(48.7 \%)$. Stunting (67.3\% vs. $60.5 \%)$ and underweight (54.4 \% vs. $42.3 \%$ ) were more prevalent in boys than girls. More children were reported as thin (11.9\%) than at risk of overweight $(3.9 \%)$ and overweight (1.3\%).

Households with a normal mother paired with an underweight/stunted child (NWM/UWSTC) (50 \%) were found to be most prevalent in the Orang Asli communities (Table 3). The coexistence of overweight/obese mother and underweight/stunted child (OWOBM/UWSTC) was observed in $20 \%$ of the Orang Asli households. There was a higher prevalence of households with overweight/obese mother-stunted child (OWOBM/STC) (19.4 \%) than households with overweight/obese mother-underweight child (OWOBM/UWC) (12.5\%).
Demographic and socio-economic factors associated with double-burden of malnutrition among mother-child pairs Factors that are significantly associated with DBM households, defined by mother overweight or obese/child underweight (OWOBM/UWC) include ethnicity and number of children (Table 4). Jah Hut (adj. OR: 0.1, $P<0.05$ ) and higher number of children (adj. OR: 0.3, $P<0.05$ ) were significantly associated with lower odds of DBM. For DBM households, defined as mother overweight or obese/child stunted (OWOBM/STC), boys (adj. OR: $8.5, P<0.05$ ), older age mothers (adj. OR: 1.2, $P<0.05$ ), mothers with higher education (adj. OR: 1.7, $P<0.05)$ and households with income per capita less than USD 29.01 (RM 97.00) (adj. OR: $16.8, P<0.01$ ) were associated with higher odds of DBM (Table 4). Boys (adj. OR: 7.2, $P<0.05$ ), mothers with higher education (adj. OR: 1.5, $P<0.05)$ and households with income per capita less than USD 29.01 (RM 97.00) (adj. OR: 11.1, $P<0.05)$ were significantly associated with DBM households, defined as mother overweight or obese/child underweight or stunted (OWOBM/UWSTC) (Table 4).

\section{Discussion}

Similar to other indigenous communities worldwide $[15,17,25]$, DBM occurs in the Orang Asli community of the current study, with a high prevalence of adult overweight/obesity coexisting with a very high prevalence of child undernutrition. This DBM phenomenon could be partially due to high proportions of stunted children and short stature of adults (i.e. women) that were observed in this Orang Asli community. In Guatemala, more indigenous women were reported to have short stature compared to non-indigenous women [36] and maternal short stature was significantly associated with overweight mother-stunted child pairs $[9,11]$. The intergenerational transmission of stunting from mother to child, in which poor intrauterine growth brought on by a malnourished/stunted mother is associated with low birth weight and stunting in early childhood [6-8]. Another possible explanation for DBM is that indigenous populations are undergoing nutrition transition [37], whereby they experience a shift from highly mobile lifestyle (subsistence farming and hunting-fishing-gathering) and traditional diets high in plant-source foods to westernized diets high in fat, sugars, salt and animal-source foods, and sedentary lifestyle $[15,25,28,38,39]$. These changes could contribute to child undernutrition and adult overweight/obesity due to impaired control of dietary energy, lower energy expenditure and a lower rate of fat oxidation [40].

At household level, we reported a higher prevalence of households with OWOBM/UWSTC (20\%) and OWOBM/ STC (19 \%) than OWOBM/UWC (13\%). Similarly, Lee et al. [11] reported that $21.5 \%$ of indigenous households in Guatemala comprised of OWOBM/STC. Several other studies have reported lower prevalence of double-burden 
Table 2 Demographic and socio-economic characteristics of Orang Asli at community and household levels

\begin{tabular}{|c|c|c|}
\hline Characteristic & $n(\%)$ & Mean $\pm S D$ \\
\hline \multicolumn{3}{|l|}{ Community level: adults ( $N=981)$} \\
\hline \multicolumn{3}{|l|}{ Ethnicity } \\
\hline Jah Hut & $851(86.7)$ & \\
\hline Temuan & $69(7.0)$ & \\
\hline Che Wong & $61(6.2)$ & \\
\hline \multicolumn{3}{|l|}{ Sex } \\
\hline Male & $455(46.4)$ & \\
\hline Female & $526(53.6)$ & \\
\hline Age (years) & & $37.3 \pm 14.9$ \\
\hline \multicolumn{3}{|l|}{ Marital status } \\
\hline Single & $197(20.1)$ & \\
\hline Married & $678(69.1)$ & \\
\hline Divorced/widow & $106(10.8)$ & \\
\hline Education (years) & & $3.7 \pm 4.2$ \\
\hline \multicolumn{3}{|l|}{ Employment } \\
\hline $\begin{array}{l}\text { Employed (employer, employee, } \\
\text { own account worker) }\end{array}$ & $459(46.8)$ & \\
\hline Unpaid family worker/housewife & $374(38.2)$ & \\
\hline Unemployed/student & $99(10.1)$ & \\
\hline Retired & $49(5.0)$ & \\
\hline Income (RM/month) & & $432.65 \pm 361.12$ \\
\hline Household size & & $6.9 \pm 3.2$ \\
\hline Number of children & & $3.0 \pm 2.2$ \\
\hline Number of schooling children & & $1.5 \pm 1.6$ \\
\hline Household income (RM/month) & & $853.32 \pm 880.23$ \\
\hline $\begin{array}{l}\text { Household income per capita } \\
\left(\mathrm{RM} / \text { month}^{\mathrm{a}}\right.\end{array}$ & & $130.61 \pm 120.04$ \\
\hline
\end{tabular}

$497(50.7)$

$273(27.8)$

$211(21.5)$

$\geq$ USD 58.02 ( $\geq$ RM 194)

Household level: mother-child pairs $(N=160)$

Ethnicity

$\begin{array}{ll}\text { Jah Hut } & 140(87.5) \\ \text { Temuan } & 7(4.4) \\ \text { Che Wong } & 13(8.1) \\ \text { Child's sex } & \\ \text { Boys } & 94(58.8) \\ \text { Girls } & 66(41.3)\end{array}$

Child's age (months)

Maternal age (years)

Maternal marital status

Married
Table 2 Demographic and socio-economic characteristics of Orang Asli at community and household levels (Continued)

\begin{tabular}{|c|c|c|}
\hline Single/divorced/widow & $8(5.0)$ & \\
\hline Maternal education (years) & & $4.0 \pm 3.6$ \\
\hline \multicolumn{3}{|l|}{ Maternal employment } \\
\hline Housewife/unpaid family worker & $145(90.7)$ & \\
\hline Employed & $15(9.4)$ & \\
\hline Maternal income (RM/month) & & $264.06 \pm 234.34$ \\
\hline Household size & & $7.3 \pm 3.3$ \\
\hline Number of children & & $3.7 \pm 2.1$ \\
\hline Number of schooling children & & $1.7 \pm 1.8$ \\
\hline Household income (RM/month) & & $851.37 \pm 779.86$ \\
\hline $\begin{array}{l}\text { Household income per capita } \\
\text { (RM/month) })^{a}\end{array}$ & & $120.24 \pm 93.38$ \\
\hline$<$ USD 29.01 (< RM 97) & $83(51.9)$ & \\
\hline USD 29.01-58.02 (RM 97-194) & $47(29.4)$ & \\
\hline$\geq$ USD 58.02 ( $\geq$ RM 194) & $30(18.8)$ & \\
\hline
\end{tabular}

households. In poor urban area of Benin (West Africa), the prevalence of households with maternal overweight/obesity and child stunting/wasting was $16.2 \%$ [41] while households with OWOBM/STC in rural Indonesia and Bangladesh were $11 \%$ and $4 \%$, respectively [9]. Jehn \& Brewis [3] showed that there were less than $10 \%$ of households with OWOBM/STC in the middle and lower income countries, except in Egypt (12.5\%), Ghana (12.5\%), Nicaragua (12.5\%), Bolivia (15\%), Peru (16 \%) and Guatemala (23\%). For households with OWOBM/UWC, the reported prevalence was lower than the prevalence reported in previous local studies [12, 13, 42]. Saibul et al. [12] reported that $25.8 \%$ of Orang Asli households in semi-urban areas had OWOBM/UWC while 26-29.6\% of Malay households in rural and semi-urban areas were with OWOBM/UWC [13, 42]. While a study among urban poor in Haiti (14.3\%) [43] reported a similar prevalence, the Demographic and Health Surveys (DHS) database from 18 middle and lower income countries in South Asia, Africa and Latin America (0.3-5.3 \%) [3] showed much lower prevalence of households with OWOBM/UWC as compared to the present study. The different prevalence of DBM across studies could be due to the different proportions of maternal overweight and child underweight/stunting across regions, countries or populations.

While several studies showed that DBM was associated with higher income and wealthier households [1, 9], others have reported that DBM was prevalent among the lower and middle income households [11, 42]. Similarly, we observed that double-burden households with 
Table 3 Nutritional status of Orang Asli at community and household levels

\begin{tabular}{|c|c|c|c|}
\hline Characteristic & Male & Female & Total \\
\hline Community level: nutritional status & $n=455$ & $n=526$ & $N=981$ \\
\hline \multicolumn{4}{|l|}{ Adults } \\
\hline Weight (kg) (Mean $\pm S D)$ & $57.9 \pm 11.7$ & $50.0 \pm 12.7$ & $53.7 \pm 12.9$ \\
\hline Height (cm) (Mean \pm SD) & $159.1 \pm 6.5$ & $147.7 \pm 6.2$ & $153.0 \pm 8.5$ \\
\hline $\begin{array}{l}\text { Body mass index }\left(\mathrm{BMl}, \mathrm{kg} / \mathrm{m}^{2}\right) \\
\text { (Mean } \pm \mathrm{SD})\end{array}$ & $22.8 \pm 4.1$ & $22.8 \pm 4.9$ & $22.8 \pm 4.6$ \\
\hline Underweight $(<18.50)$ & $38(8.4)$ & $89(16.9)$ & $127(12.9)$ \\
\hline Normal (18.50-24.99) & $310(68.1)$ & $294(55.9)$ & $604(61.6)$ \\
\hline Overweight (25.00-29.99) & $80(17.6)$ & $101(19.2)$ & $181(18.5)$ \\
\hline Obese ( $\geq 30.00)$ & $27(5.9)$ & $42(8.0)$ & $69(7.0)$ \\
\hline \multicolumn{3}{|l|}{$\begin{array}{l}\text { Mothers of children below } \\
5 \text { years }\end{array}$} & $N=205$ \\
\hline \multicolumn{3}{|l|}{ Weight (kg) (Mean $\pm S D)$} & $52.0 \pm 11.0$ \\
\hline \multicolumn{3}{|l|}{ Height $(\mathrm{cm})($ Mean $\pm S D)$} & $148.7 \pm 4.9$ \\
\hline \multicolumn{3}{|l|}{ Body mass index (BMl, kg/m²) } & $23.5 \pm 4.3$ \\
\hline \multicolumn{3}{|l|}{ Underweight $(<18.50)$} & $14(6.8)$ \\
\hline \multicolumn{3}{|l|}{ Normal (18.50-24.99) } & $128(62.4)$ \\
\hline \multicolumn{3}{|l|}{ Overweight (25.00-29.99) } & $49(23.9)$ \\
\hline \multicolumn{3}{|l|}{ Obese $(\geq 30.00)$} & $14(6.9)$ \\
\hline Children below 5 years & $n=162$ & $n=142$ & $N=304$ \\
\hline \multicolumn{4}{|l|}{$\begin{array}{l}\text { Weight-for-age (WAZ) } \\
(\text { Mean } \pm \text { SD) }\end{array}$} \\
\hline \multicolumn{4}{|l|}{$\begin{array}{l}\text { Severe underweight } \\
(<-3.0 \mathrm{SD})\end{array}$} \\
\hline \multicolumn{4}{|l|}{$\begin{array}{l}\text { Moderate underweight } \\
(-3.0 \text { to }<-2.0 \mathrm{SD})\end{array}$} \\
\hline Normal (-2.0 to 2.0 SD) & \multicolumn{3}{|c|}{ Normal (-2.0 to 2.0 SD) $\quad 74$ (45.7) } \\
\hline Height-for-age (HAZ) (Mean $\pm S D)$ & $-2.5 \pm 1.3$ & $-2.3 \pm 1.2$ & $-2.4 \pm 1.2$ \\
\hline \multicolumn{4}{|l|}{ Severe stunting $(<-3.0 \mathrm{SD})$} \\
\hline \multicolumn{4}{|l|}{$\begin{array}{l}\text { Moderate stunting } \\
(-3.0 \text { to }<-2.0 \mathrm{SD})\end{array}$} \\
\hline \multicolumn{4}{|l|}{ Normal (-2.0 to 2.0 SD) } \\
\hline \multicolumn{4}{|l|}{$($ Mean $\pm S D)$} \\
\hline Severe thinness $(<-3.0 \mathrm{SD})$ & $4(2.5)$ & $2(1.4)$ & $6(2.0)$ \\
\hline \multicolumn{4}{|l|}{$\begin{array}{l}\text { Moderate thinness } \\
(-3.0 \text { to }<-2.0 \mathrm{SD})\end{array}$} \\
\hline Normal $(-2.0$ to $<1.0$ SD) & $133(82.1)$ & 119 (83.8) & $252(82.9)$ \\
\hline $\begin{array}{l}\text { At risk overweight } \\
(1.0 \text { to }<2.0 \mathrm{SD})\end{array}$ & $5(3.1)$ & $7(4.9)$ & $12(3.9)$ \\
\hline Overweight (2.0 and above) & $2(1.2)$ & $2(1.4)$ & $4(1.3)$ \\
\hline \multicolumn{3}{|l|}{$\begin{array}{l}\text { Household level: classification of } \\
\text { nutritional status of mother-child pairs }\end{array}$} & $N=160$ \\
\hline \multicolumn{4}{|l|}{$\mathrm{BMI}_{\text {mother }} \mathrm{Vs} . \mathrm{WAZ} Z_{\text {child }}$} \\
\hline \multicolumn{3}{|l|}{ NWM/NWC } & $41(25.6)$ \\
\hline \multicolumn{3}{|l|}{ OWOBM/UWC } & $20(12.5)$ \\
\hline \multicolumn{3}{|l|}{ OWOBM/NWC } & $34(21.3)$ \\
\hline
\end{tabular}

Table 3 Nutritional status of Orang Asli at community and household levels (Continued)

\begin{tabular}{|c|c|}
\hline UWM/UWC & $7(4.4)$ \\
\hline UWM/NWC & $2(1.3)$ \\
\hline NWM/UWC & $56(35.0)$ \\
\hline \multicolumn{2}{|l|}{$\mathrm{BMI}_{\text {mother }} \mathrm{vs} . \mathrm{HAZ} \mathrm{Z}_{\text {child }}$} \\
\hline NWM/NHC & $20(12.5)$ \\
\hline OWOBM/STC & $31(19.4)$ \\
\hline OWOBM/NHC & $23(14.4)$ \\
\hline UWM/STC & $7(4.4)$ \\
\hline UWM/NHC & $2(1.3)$ \\
\hline NWM/STC & $77(48.1)$ \\
\hline \multicolumn{2}{|c|}{$B M I_{\text {mother }}$ vs. WAZ/HAZ $Z_{\text {child }}$} \\
\hline NWM/NWNHC & $17(10.6))$ \\
\hline OWOBM/UWSTC & $32(20.0)$ \\
\hline OWOBM/NWNHC & $22(13.8)$ \\
\hline UWM/UWSTC & $8(5.0)$ \\
\hline UWM/NWNHC & $1(0.6)$ \\
\hline NWM/UWSTC & $80(50.0)$ \\
\hline \multicolumn{2}{|c|}{$\begin{array}{l}\text { NWM/NWC normal weight mother/normal weight child, OWOBM/UWC } \\
\text { overweight or obese mother/underweight child, OWOBM/NWC overweight or } \\
\text { obese mother/normal weight child, UWM/UWC underweight mother/ } \\
\text { underweight child, UWM/NWC underweight mother/normal weight child, } \\
\text { NWM/UWC normal weight mother/underweight child, NWM/NHC normal } \\
\text { weight mother/normal height child, OWOBM/STC overweight or obese mother/ } \\
\text { stunted child, OWOBM/NHC overweight or obese mother/normal height child, } \\
\text { UWM/STC underweight mother/stunted child, UWM/NHC underweight mother/ } \\
\text { normal height child, NWM/STC normal weight mother/stunted child, NWM/ } \\
\text { NWNHC normal weight mother/normal weight and height child, OWOBM/ } \\
\text { UWSTC overweight or obese mother/underweight or/and stunted child, } \\
\text { OWOBM/NWNHC overweight or obese mother/normal weight and height child, } \\
\text { UWM/UWSTC underweight mother/underweight or/and stunted child, UWM/ } \\
\text { NWNHC underweight mother/normal weight and height child, NWM/UWSTC } \\
\text { normal weight mother/underweight or/and stunted child }\end{array}$} \\
\hline
\end{tabular}

OWOBM/STC and OWOBM/UWSTC were more likely to occur in lower income households (households income per capita < USD 29.01). Inadequate resources to purchase quality foods may contribute to the purchase of cheaper energy-dense and nutrient-poor foods by lower income households to maintain families' daily dietary intakes at less cost [44]. The consumption of these foods may predispose children to poor growth and development due to inadequate important nutrients and energy, particularly if small amounts are consumed, but may provide excess calories for adults [37].

We found that the OWOBM/UWC households were more prevalent in the non-Jah Hut (Temuan and Che Wong). For Jah Hut, while there is increasing dependence on rubber/oil palm cultivation, subsistence farming and hunting-fishing-gathering are still important food activities [25]. The involvement of Jah Hut women in these activities may sustain the dependence on traditional food sources and physical activity level. Living near to the town area might explain the easier access to 
Table 4 Association of demographic and socio-economic characteristics with 3 different definitions of mother-child with double-burden of malnutrition

\begin{tabular}{|c|c|c|c|c|c|c|}
\hline \multirow{2}{*}{$\begin{array}{l}\text { Demographic and } \\
\text { socio-economic characteristics }\end{array}$} & \multicolumn{2}{|c|}{ OWOBM/UWC $(n=20)^{a}$} & \multicolumn{2}{|c|}{ OWOBM/STC $(n=31)^{b}$} & \multicolumn{2}{|c|}{ OWOBM/UWSTC $(n=32)^{c}$} \\
\hline & $\begin{array}{l}\text { Crude OR } \\
(95 \% \mathrm{Cl})\end{array}$ & $\begin{array}{l}\text { Adjusted OR } \\
(95 \% \mathrm{Cl})\end{array}$ & $\begin{array}{l}\text { Crude OR } \\
(95 \% \mathrm{Cl})\end{array}$ & $\begin{array}{l}\text { Adjusted OR } \\
(95 \% \mathrm{Cl})\end{array}$ & $\begin{array}{l}\text { Crude OR } \\
(95 \% \mathrm{Cl})\end{array}$ & $\begin{array}{l}\text { Adjusted OR } \\
(95 \% \mathrm{Cl})\end{array}$ \\
\hline \multicolumn{7}{|l|}{ Ethnicity $^{e}$} \\
\hline Jah Hut & $0.2(0.0-1.2)$ & $0.1(0.0-0.6)^{*}$ & $0.8(0.1-4.5)$ & $0.7(0.1-5.7)$ & $0.4(0.1-4.3)$ & $0.4(0.0-5.1)$ \\
\hline Temuan and Che Wong ${ }^{d}$ & 1.0 & 1.0 & 1.0 & 1.0 & 1.0 & 1.0 \\
\hline \multicolumn{7}{|l|}{ Child's sex ${ }^{f}$} \\
\hline Boys & $1.5(0.5-4.4)$ & $2.4(0.6-10.3)$ & $1.9(0.6-6.1)$ & $8.5(1.3-53.0)^{*}$ & $1.9(0.6-6.2)$ & $7.2(1.2-44.4)^{*}$ \\
\hline Girls $^{d}$ & 1.0 & 1.0 & 1.0 & 1.0 & 1.0 & 1.0 \\
\hline Child's age (months) $^{f}$ & $1.0(1.0-1.1)^{*}$ & $1.1(1.0-1.1)$ & $1.0(1.0-1.1)$ & $1.0(0.9-1.0)$ & $1.0(1.0-1.1)$ & $1.0(1.0-1.0)$ \\
\hline Maternal age (years) ${ }^{g}$ & $1.1(1.0-1.1)$ & $1.0(0.9-1.2)$ & $1.1(1.0-1.2)$ & $1.2(1.0-1.4)^{*}$ & $1.1(1.0-1.1)$ & $1.2(1.0-1.3)$ \\
\hline Maternal education ${ }^{g}$ & $0.9(0.8-1.1)$ & $1.0(0.8-1.3)$ & $1.0(0.8-1.2)$ & $1.7(1.1-2.6)^{*}$ & $1.0(0.8-1.2)$ & $1.5(1.0-2.3)^{*}$ \\
\hline No of children ${ }^{\mathrm{h}}$ & $1.1(0.8-1.4)$ & $0.3(0.1-0.9)^{*}$ & $1.3(1.0-1.8)$ & $1.1(0.5-2.6)$ & $1.2(0.9-1.6)$ & $1.0(0.4-2.2)$ \\
\hline \multicolumn{7}{|l|}{ Household income per capita ${ }^{9}$} \\
\hline$<$ USD $29.60(<$ RM 97.00) & $1.3(0.4-3.8)$ & $1.9(0.5-7.9)$ & $4.2(1.3-14.2)^{*}$ & $16.8(2.4-117.3)^{* *}$ & $3.1(0.9-10.4)$ & $11.1(1.7-75.1)^{*}$ \\
\hline$\geq$ USD $29.60(\geq \text { RM 97.00 })^{d}$ & 1.0 & 1.0 & 1.0 & 1.0 & 1.0 & 1.0 \\
\hline
\end{tabular}

OWOBM/UWC overweight or obese mother/underweight child, NWM/NWC normal weight mother/normal weight child, OWOBM/STC overweight or obese mother/stunted child, NWM/NHC normal weight mother/normal height child, OWOBM/UWSTC overweight or obese mother/underweight or/and stunted child, NWM/NWNHC normal weight mother/normal weight and height child

USD $1=$ RM 3.30

${ }^{*} P<0.05 ; * * 0<0.01$

Reference group for outcome/dependent variables:

${ }^{\mathrm{a}} \mathrm{NWM} / \mathrm{NWC}(n=41)$

${ }^{\mathrm{b}} \mathrm{NWM} / \mathrm{NHC}(n=20)$

${ }^{c} \mathrm{NWM} / \mathrm{NWNHC}(n=17)$

${ }^{\mathrm{d}}$ Reference group for independent variables

eEthnicity variable was adjusted for household size, no of children, no of schooling children and household income per capita

fEach variable was adjusted for child's sex and age, and maternal age and education

${ }^{9}$ Each variable was adjusted for child's sex and age, maternal age and education, household size, no of children and household income per capita

${ }^{h}$ No of children variable was adjusted for child's sex and age, ethnicity, household size, no of schooling children and household income per capita

processed foods by the Che Wong and Temuan, although the Che Wong (mostly men) still maintains huntingfishing-gathering activities [24, 38]. Studies have shown that Che Wong and Temuan tend to depend on relatively inexpensive processed foods (e.g. sweetened condensed milk, sugar and cooking oil) that can be purchased at the nearest sundry shops/town when income is inadequate and forest resources for food and economy dwindle due to the monsoon season [12, 24, 39].

In the present study, boys were more likely to be in DBM households with OWOBM/STC and OWOBM/UWSTC. However, several studies demonstrated that female children were more likely to be in households with OWOBM/STC $[4,9]$. A plausible explanation for the inconsistent findings is sex differences in child nutritional status across countries. For example, boys were more likely to be stunted than girls in Sub-Saharan Africa [45] whereas girls tend be more stunted than boys in Bangladesh [46]. A higher stunting prevalence among boys than girls in the present sample might explain the association between DBM and male child gender. In addition, cultural influence on child feeding and caring due to power relations and social norms that perpetuate discriminatory attitudes and practices may also contribute to the sex differences in DBM [47].

Several maternal characteristics were associated with DBM, including higher maternal education and older mother. Numerous studies have reported that higher maternal education was protective against DBM $[3,9,11,42,48]$. However, the present study and a study in rural Bangladesh [9] showed that doubleburden of OWOBM/STC was more likely to occur in households where mothers had higher education level. The conflicting findings underscore the complexities of the association between maternal education and DBM. Maternal education may not necessarily be sufficient to initiate behavioral change related to health and nutrition [49]. Lacking of health and nutrition knowledge could contribute to women being less sensitive to child and own health or less responsive to health and nutrition issues due to barriers such as food cost, accessibility and availability, lack cooking skill and equipment $[44,49]$. On the other hand, our findings, together with previous studies [3,9] showed that older mothers were associated with double-burden of 
OWOBM/STC. Reduced physical activity due to physical exertion decreases with age may contribute to overweight and obesity among older mothers in DBM households [10].

We showed that OWOBM/UWC was less likely to occur in households with higher number of children. In contrast, Jehn \& Brewis [3] reported that having more children in the households was associated with increased risk of OWOBM/UWC. However, it should be noted that we considered children $<18$ years while Jehn \& Brewis [3] investigated young siblings $<5$ years. Different age ranges in defining "number of children in the same household" in both studies may explain these different findings. We also found that in this sample, number of children in the household increased with household size, number of schooling children and household income (data not shown). As many of schooling Orang Asli children are staying at school hostel during school terms, the number of children living in the household is lesser which could mean more resources for family members (i.e., food, time and money) [48]. It could also mean that having many children, particularly older ones, provides extra hands to care for younger siblings or contribute to household income.

There are several limitations to the present study. The cross-sectional study design to investigate the association of demographic and socio-economic factors with DBM could not determine the cause and effect relationship. In addition the small sample size, inclusion of only three sub-tribes and specific study location could limit the generalization of study findings to indigenous peoples of Peninsular Malaysia. The small sample size could also limit additional multivariate analyses to compare DBM households with other household phenotypes and limit the number of variables that could be included in the multivariate models. The present study did not examine other important determinants of DBM such as dietary intake, physical activity, caregiving practices, cultural influences, pregnancy and birth information. Finally, as the operational definition of "double-burden of malnutrition" varied across studies, comparing the prevalence and determinants of DBM with other countries and within different contexts is inevitably difficult. Despite these limitations, the present study has provided important information on DBM in indigenous communities and its socio-demographic characteristics which could be the basis for strategies to improve health and nutrition of the Orang Asli.

\section{Conclusions}

DBM is a public health concern in lower income communities undergoing nutrition and socio-economic transition, and the Orang Asli population in Peninsular Malaysia is not spared. Undernutrition in early childhood needs to be addressed as underweight or/and stunted children may be predisposed to be overweight and obese in adulthood [50, 51]. The insights on demographic and socio-economic factors associated with DBM underscore the importance of having effective and culturally sensitive strategies to simultaneously address undernutrition and over-nutrition in children and adults, respectively. Poverty reduction, access to quality diet and improved health and nutrition literacy would be important and useful strategies to address the coexistence of DBM in this population.

\section{Abbreviations}

DBM: Double-burden of malnutrition; KWR: Krau Wildlife Reserve; PERHILITAN: Department of Wildlife and National Parks Peninsular Malaysia; JAKOA: Department of Orang Asli Development; WAZ: Weight-for-age; HAZ: Height-for-age; BAZ: Body mass index-for-age; SD: Standard deviation; BMI: Body mass index; OWOBM: Overweight or obese mother; NWM: Normal weight mother; UWM: Underweight mother; STC: Stunted child; NHC: Normal height child; UWC: Underweight child; NWC: Normal weight child; STUWC: Stunted or/and underweight child; NHNWC: Normal height and weight child; OWOBM/STC: Overweight or obese mother/stunted child; OWOBM/UWC: Overweight or obese mother/underweight child; OWOBM/UWSTC: Overweight or obese mother/underweight and/or stunted child; NWM/NHC: Normal weight mother/normal height child; NWM/NWC: Normal weight mother and child; NWM/NWNHC: Normal weight mother/normal weight and height child; OR: Odds ratios; Adj. OR: Adjusted odds ratios; Cl: Confidence interval; RM: Ringgit Malaysia; USD: United States Dollar; WHO: World Health Organization.

\section{Competing interests}

The authors declare that they have no competing interests.

\section{Authors' contributions}

All authors substantially contributed to the study and the manuscript. WCY participated in study design, data collection, data analysis, data interpretation and manuscript preparation; ZMS participated in study conceptualization, study design, data interpretation, manuscript preparation and finalization; CEY participated in data collection; NS, CYS and SNAA participated in study design, read and approved the manuscript.

\section{Acknowledgements}

We thank AJINOMOTO CO., INC. (Tokyo) and Universiti Putra Malaysia for the financial support and the study participants for their time and cooperation.

Received: 14 April 2015 Accepted: 14 July 2015

Published online: 21 July 2015

\section{References}

1. Doak CM, Adair L, Bentley M, Monteiro C, Popkin BM. The dual burden household and the nutrition transition paradox. Int J Obes. 2005;29:129-36. http://www.nature.com/ijo/journal/v29/n1/abs/0802824a.html

2. Garrett J, Ruel M. Stunted child-overweight mother pairs: prevalence and association with economic development and urbanization. FNB. 2005;26:209-21.

3. Jehn $M$, Brewis A. Paradoxical malnutrition in mother-child pairs: untangling the phenomenon of over- and under-nutrition in underdeveloped economies. Econ Hum Biol. 2009;7:28-35.

4. Lee J, Houser RF, Must A, de Fulladolsa PP, Bermudez OI. Disentangling nutritional factors and household characteristics related to child stunting and maternal overweight in Guatemala. Econ Hum Biol. 2010;8:188-96.

5. Barnett I. Is the dual burden of over- and under-nutrition a concern for poor household in Ethiopia, India, Peru, and Vietnam? Working Paper No.67. Young Lives: UK; 2011.

6. Gluckman PD, Hanson M. The fetal matrix: evolution, development, and disease. Cambridge: Cambridge University Press; 2004.

7. Sawaya AL, Martins PA, Grillo LP, Florencio TT. Long-term effects of early malnutrition on body weight regulation. Nutr Rev. 2004;62:S127-33. doi:10.1111/j.1753-4887.2004.tb00082.x 
8. Victora CG, Adair L, Fall C, Hallal PC, Martorell R, Richter L, et al. Maternal and child undernutrition: consequences for adult health and human capital. Lancet. 2008;371:340-57.

9. Oddo VM, Rah JH, Semba RD, Sun K, Akhter N, Sari M, et al. Predictors of maternal and child double burden of malnutrition in rural Indonesia and Bangladesh. Am J Clin Nutr. 2012;95:951-8. doi:10.3945/ajen.111.026070.

10. Popkin BM. The nutrition transition in low income countries: an emerging crisis. Nutr Rev. 1994;52:285-98.

11. Lee J, Houser RF, Must A, de Fuladolsa PP, Bermudez Ol. Socioeconomic disparities and the familial coexistence of child stunting and maternal overweight in Guatemala. Econ Hum Biol. 2012;10:232-41. doi:10.1016/j.ehb.2011.08.002.

12. Saibul N, Shariff ZM, Lin KG, Kandiah M, Ghani NA, Rahman HA. Food variety score is associated with dual burden of malnutrition in Orang Asli (Malaysian indigenous peoples) households: implications for health promotion. Asia Pac J Clinl Nutr. 2009;18:412-22.

13. Ihab AN, Rohana AJ, Wan Manan WM, Wan Suriati WN, Zalilah MS, Rusli AM. The coexistence of dual burden of malnutrition in a sample of rural Malaysia. Int J Prev Med. 2013;4(6):690-9.

14. World Bank. Still among the poorest of the poor. Indigenous People country brief. Washington, DC: World Bank; 2011. http://documents.worldbank.org/ curated/en/2011/10/15198880/still-among-poorest-poor

15. Burns J, Thomson N. Review of nutrition and growth among indigenous peoples. Australian Indigenous HealthlnfoNet. 2008; http://www.healthinfonet.ecu.edu.au/nutrition_review

16. Horta BL, Santos RV, Welch JR, Cardosa AM, dos Santos JV, Assis AMO, et al. Nutritional status of indigenous children: findings from the First National Survey of Indigenous People's Health and Nutrition in Brazil. Int J Equity Health. 2013:12:23.

17. Coimbra CEA, Santos RV, Welch JR, Cardosa AM, Souza MC, Garnelo L, et al. The First National Survey of Indigenous People's Health and Nutrition in Brazil: rationale, methodology, and overview of results. BMC Public Health. 2013;13.

18. Australian Indigenous HealthInfoNet. Review of diabetes among Indigenous peoples. Australian Indigenous HealthInfoNet. 2007; http://www.healthinfonet.ecu.edu.au/chronic-conditions/diabetes/ reviews/our-review

19. Gray C, Brown A, Thomson N. Review of cardiovascular health among Indigenous Australians. Australia: Australian Indigenous HealthlnfoNet; 2012. http://www.healthinfonet.ecu.edu.au/chronic-conditions/cvd/reviews/ heart_review

20. National Collaborating Centre for Aboriginal Health [NCCAH]. The state of knowledge of Aboriginal health: a review of aboriginal public health in Canada. Prince George, BC: Author; 2012.

21. Norfariza Hanim K. Population and housing census of Malaysia 2000: Orang Asli in Peninsular Malaysia. Monograph Series No. 3. Malaysia: Department of Statistics; 2008; http://www.statistics.gov.my

22. Shashikala S, Kandiah M, Zalilah MS, Khor GL. Nutritional status of 1-3 year old child and maternal care behaviours in the Orang Asli Malaysia. S Afr J Clin Nutr. 2005;18:173-80

23. Hayati MY, Ting SC, Roshita I, Safiih L. Anthropometric indices and lifestyle practices of the indigenous Orang Asli adults in Lembah Belum, Grik of Peninsular Malaysia. Asia Pac J Clin Nutr. 2007;16(1):49-55.

24. Haemamalar K, Zalilah MS, Neng AA. Nutritional status of Orang Asli (Che Wong tribe) adults in Krau Wildlife Reserve, Pahang. Mal J Nutr. 2010;16(1):55-68.

25. Chua EY, Zalilah MS, Chin YS, Norhasmah S. Dietary diversity is associated with nutritional status of Orang Asli children in Krau Wildlife Reserve, Pahang. Mal J Nutr. 2012;18(1):1-13.

26. Osman A, Tan TT, Sakinah O, Khalid BAK, Wu LL, Ng ML. Prevalence of NIDDM and impaired glucose tolerance in aborigines and Malays in Malaysia and their relationship to sociodemographic, health, and nutritional factors. Diabetes Care. 1993;16(1):68-75. doi:10.2337/diacare.16.1.68

27. Wan Nazaimoon WM, Suraiami M. Prevalence of diabetes, impaired fasting glucose and metabolic syndrome among female Orang Asli community in Peninsular Malaysia. Int J Diab Dev Ctries. 2010;30:118-22. doi:10.4103/0973-3930.66503.

28. Phipps ME, Chan KKL, Naidu R, Mohamad NW, Hoh BP, Quek KF, et al. Cardio-metabolic health risks in indigenous populations of Southeast Asia and the influence of urbanization. BMC Public Health. 2015;15:47.

29. Department of Wildlife and National Parks Peninsular Malaysia (PERHILITAN). Krau Wildlife Reserve, Pahang. Peninsular Malaysia: Department of Wildlife and National Parks Peninsular Malaysia; 2012. http://www.wildlife.gov.my Accessed 28 Jun 2012

30. Department of Orang Asli Affairs (JAKOA). Household distribution of Orang Asli in Krau Wildlife Reserve, Pahang. Malaysia, Pahang: Department of Orang Asli Affairs; 2011-2012.

31. WHO. Physical status: the use and interpretation of anthropometry. WHO Technical Report Series. Geneva, Switzerland: World Health Organization (WHO); 1995.

32. WHO Multicentre Growth Reference Study Group. WHO child growth standards: length/height-for-age, weight-for-age, weight-for-length and body mass index-for-age: Methods and Development. Geneva: WHO; 2006

33. Doak C, Adair L, Bentley M, Fengying Z, Popkin BM. Overweight and underweight coexist within households in Brazil, China and Russia. Public Health Nutr. 2002;5:215-21.

34. Varela-Silva Ml, Dickinson F, Wilson H, Azcorra H, Griffiths PL, Bogin B. The nutritional dual-burden in developing countries - how is it assessed and what are the health implications? Coll Antropol. 2012;1:39-45.

35. The Economic Planning Unit. Tenth Malaysia plan 2011-2015. Putrajaya, Malaysia: The Economic Planning Unit, Prime Minister's Department; 2010.

36. Pan American Health Organization. Guatemala, Health in Americas. 2007; www1.paho.org/hia/archivosvol2/paisesing/Guatemala\%20English.pdf.

37. Caballero B. A nutrition paradox - underweight and obesity in developing countries. N Eng J Med. 2005;14:1514-6.

38. Fadli AR, Adzrool Idzwan I, Kamarudzaman MI, Mustaffa Halabi HA. The impact of Che Wong tribe resettlement through image representation: the documentation of Che Wong tribe at Kuala Gandah, Lanchang Pahang Malaysia. IPEDR. 2012;51:40

39. Khor GL. Resettlement and nutritional implications: the case of Orang Asli in regroupment schemes. Pertanika J Soc Sci \& Hum. 1994;2(2):123-32.

40. Sawaya AL, Robert S. Stunting and future risk of obesity: principal of physiological mechanism. Cadernos Saude Publica. 2003;19 Suppl 1:S21-8.

41. Bouzitou DNG, Fayomi B, Delisle H. Child malnutrition and maternal overweight in the same households in poor urban areas of Benin. Sante. 2005; 15:263-70.

42. Khor GL, Sharif ZM. Dual forms of malnutrition in the same households in Malaysia - a case study among Malay rural households. Asia Pac J Clin Nutr. 2003;12:427-37.

43. Raphael D, Delisle H. Households with undernourished children and overweight mothers: Is this a concern for Haiti? Ecol Food Nutr. 2005;44:147-65.

44. Darmon N, Drewnowski A. Does social class predict diet quality? Am J Clin Nutr. 2008;87:1107-17.

45. Wamani H, Astrøm AN, Peterson S, Tumwine JT, Tylleskär T. Boys are more stunted than girls in Sub-Saharan Africa: a meta-analysis of 16 demographic and health surveys. BMC Pediatr. 2007;7:17.

46. Dancer D, Rammohan A, Smith MD. Infant mortality and child nutrition in Bangladesh. Health Econ. 2008;17(9):1015-35.

47. United Nations Children's Fund. Tracking progress on child and maternal nutrition. New York, NY: UNICEF; 2009

48. Angeles-Agdeppa I, Lana RD, Barba CVC. A case study on dual forms of malnutrition among selected households in District 1, Tondo, Manila. Asia Pac J Clin Nutr. 2003;12:438-46.

49. Beydoun MA, Wang Y. Do nutrition knowledge and beliefs modify the association of socio-economic factors and diet-quality among US adults? Prev Med. 2008:46:145-5.

50. Barker DJP, Osmond C, Forsen TJ, Kajantie E, Eriksson JG. Trajectories of growth among children who have coronary events as adults. N Eng J Med. 2005;353:1802-9. doi:10.1056/NEJMoa044160.

51. Ramachandran P. Maternal \& child nutrition: new dimensions of dual nutrition burden. Indian J Med Res. 2009;130:575-8. 